\title{
Avaliação de ionóforos pela técnica da perda do potássio celular e produção de gases in vitro
}

[Ionophores evaluation by intracellular potassium depletion and in vitro gas production]

\author{
W.M. Leopoldino ${ }^{1,4}$, R.P. Lana ${ }^{1,4}$, E.C. Eifert ${ }^{1,4}$, P.B. Arcuri ${ }^{2}$, H.C. Mantovani ${ }^{3,4}$, R.G.R. Martins ${ }^{1,5}$ \\ ${ }^{1}$ Departamento de Zootecnia - UFV - Viçosa, MG \\ ${ }^{2}$ Embrapa - Gado de Leite - Juiz de Fora, MG \\ ${ }^{3}$ Departamento de Microbiologia - UFV - Viçosa, MG \\ ${ }^{4}$ Bolsista do CNPq \\ ${ }^{5}$ Bolsista da CAPES
}

\begin{abstract}
RESUMO
Dois estudos foram realizados com vacas lactantes utilizadas como unidade experimental e doadoras de líquido ruminal, sendo as populações de bactérias utilizadas para avaliar a ação de níveis crescentes de lasalocida e monensina na resistência à perda de potássio intracelular, e para produção de gases in vitro. A perda de potássio $\left(\mathrm{K}_{\max }\right)$ da lasalocida foi menor para a população de bactérias obtidas do líquido de rúmen de vacas submetidas a dietas com monensina, óleo de soja e monensina mais óleo de soja $(19,4$ a $25,4 \%)$ quando comparada com a perda de potássio em vacas submetidas a dietas sem ionóforo e óleo de soja $(30,1 \%)$. O mesmo ocorreu para a perda de potássio da monensina, em que o menor valor foi de 6,5\% para monensina mais óleo e o maior, de $29,5 \%$, para o controle. Necessita-se de alta concentração de monensina $\left(\mathrm{K}_{\mathrm{d}}=2,3 \mu \mathrm{M}\right)$, porém baixa de lasalocida $\left(\mathrm{K}_{\mathrm{d}}=0,2 \mu \mathrm{M}\right)$ para causar a metade da perda máxima de potássio intracelular da população de bactérias do rúmen de vacas submetidas a dietas com monensina. As populações de bactérias de vacas submetidas às dietas com monensina foram sensíveis à lasalocida. As amostras incubadas com própolis produziram menor volume de gases $(12,9 \mathrm{ml} / 100 \mathrm{~g}$ de $\mathrm{MS})$.
\end{abstract}

Palavras-chave: vaca, fermentação, lasalocida, monensina, potássio, produção de gases, ionóforo, própolis

\begin{abstract}
Two studies were carried out with lactating cows as experimental units and ruminal fluid donors. The ruminal bacteria population was used to evaluate the action of increasing levels of lasalocid and monensin on resistance of intracellular potassium depletion and in vitro gas production intracellular depletion potassium $\left(K_{\max }\right)$ of lasalocid was lower to ruminal bacteria population obtained from rumen of cows fed diets with monensin, soybean oil and monensin plus soybean oil (19.4 to 25.4\%) when compared to cows fed with control diet $(30.1 \%)$. The same occurred for intracellular depletion potassium $\left(K_{\max }\right)$ of monensin, in which the lowest value was $6.5 \%$ to monensin plus soybean oil and the greatest was $29.5 \%$ to control. High monensin concentration $\left(K_{d}=2.3 \mu \mathrm{M}\right)$ and low lasalocid concentration $\left(K_{d}=0.2 \mu \mathrm{M}\right)$ were necessary to cause half of maximum potassium depletion in ruminal bacteria population from cows fed diet with monensin. The ruminal bacteria population from cows feed diet with monensin were sensible to lasalocid. In vitro gas production showed the lowest volume when diets were incubated with propolis $(12,9 \mathrm{ml} / 100 \mathrm{~g}$ of $\mathrm{DM})$.
\end{abstract}

Keywords: cow, fermentation, lasalocid, monensin, gas production, ionophor, potassium, propolis

\section{INTRODUÇ̃̃O}

A adição de óleo na dieta de vacas em lactação, além de causar redução significativa na porcentagem de gordura do leite, tem mostrado efeito germicida e bacteriostático, principalmente sobre as bactérias Gram-positivas (Henderson, 1973). Esses efeitos têm reflexos diretos sobre a

Recebido em 31 de maio de 2007

Aceito em 24 de outubro de 2007

E-mail: wleopoldino@yahoo.com

Apoio: CNPq - Proc. 477530/01-0(NV) 
fermentação ruminal, causando redução na produção de metano e aumento no propionato, melhorando, assim, o desempenho animal e reduzindo a poluição ambiental.

Os antibióticos ionóforos, tais como monensina e lasalocida, também inibem principalmente as bactérias Gram-positivas, uma vez que a resistência aos ionóforos está relacionada à presença de uma membrana externa, de natureza lipopolissacarídica, existente em bactérias Gramnegativas (Russell e Strobel, 1988). A monensina catalisa não apenas trocas de prótons e sódio da membrana plasmática, como também permite trocas de prótons e potássio. A lasalocida também age como um mono ou bivalente antiporte metal-próton, mas possui maior afinidade por potássio (Pressman, 1973; 1976). Isso possibilita medir a ação do ionóforo por meio do potássio perdido pela célula.

A concentração inibitória mínima (CIM) é freqüentemente utilizada para descrever a potência dos antibióticos, mas esse parâmetro não pode ser aplicado para antibióticos lipofílicos como a monensina e lasalocida. Pois o líquido do meio de cultura livre de células tem pouco ionóforo e sua dose efetiva é altamente dependente da concentração celular (Chow e Russell, 1990). Trabalhos têm mostrado que a monensina e lasalocida têm habilidade de ligarem-se não especificamente às bactérias resistentes ao ionóforo, bem como às partículas de alimentos (Chow et al., 1994), logo a concentração do ionóforo livre varia muito, o que dificulta a utilização da CIM. A perda de potássio celular dependente do ionóforo, portanto, pode prover um índice sensível e fisiológico da resistência à monensina (Lana e Russell, 1996).

Assim como os ionóforos, os suplementos lipídicos insaturados apresentam efeito tóxico sobre as bactérias Gram-positivas do rúmen (Nagaraja et al., 1997), alterando a relação acetato:propionato, com produção de propionato às custas de acetato, redução da produção de metano e diminuição da amônia ruminal (Jenkins, 1993; Bateman e Jenkins, 1998; Leopoldino et al., 2005).
A produção de gases, metano e carbônico, e sua eliminação para o meio, representa perda de energia do ecossistema ruminal proveniente do alimento digerido. Além disso, esses gases eliminados, por eructação, são responsáveis em parte pelo efeito estufa e destruição da camada de ozônio da atmosfera (Chynoweth, 1996). A utilização, portanto, de substâncias que reduzam essa perda de energia na forma de gases é de grande utilidade na alimentação de ruminantes. Stradiotti et al. (2002) evidenciaram, em estudo in vitro com populações de bactérias do rúmen, que o extrato etanólico de própolis $(0,3 \mathrm{~g} / \mathrm{ml}$ de etanol a 70\%, seguida de diluição 2:1 em etanol a $70 \%$ em água) foi eficiente em reduzir a produção de gases total (somatório dos parâmetros) e produção final (cada parâmetro) de gases para carboidratos fibrosos e não fibrosos, inclusive suplantando a monensina.

Este trabalho teve como objetivos utilizar a técnica in vitro para medir a perda de potássio celular, por ação de níveis crescentes dos ionóforos monensina e lasalocida na população de bactérias do rúmen de vacas submetidas a dietas com ou sem monensina e com ou sem óleo de soja, e avaliar a produção total de gases in vitro das rações com ou sem óleo de soja incubadas com monensina, lasalocida ou própolis.

\section{MATERIAL E MÉTODOS}

Foram realizados dois experimentos. No primeiro, quatro vacas mestiças (Holandês x Zebu) lactantes, fistuladas no rúmen e estabuladas, foram mantidas num esquema de quadrado latino durante 88 dias. Os animais receberam dietas com diferentes relações concentrado : volumoso conforme Tab. 1.

Os tratamentos foram: controle - dieta 1, básica sem óleo e sem monensina; monensina - dieta 2, básica mais 33ppm de monensina; óleo - dieta 3, básica mais $4 \%$ de óleo de soja; e monensina mais óleo dieta 4 , básica mais 33ppm de monensina e $4 \%$ de óleo de soja. Os animais foram alimentados duas vezes ao dia, às 7 e $15 \mathrm{~h}$, e a coleta de líquido ruminal foi realizada duas horas após a alimentação da manhã. 
Tabela 1. Composição das dietas fornecidas para as vacas no primeiro experimento

\begin{tabular}{lcc} 
& \multirow{2}{*}{ Parâmetros } & \multicolumn{2}{c}{ Relação concentrado:volumoso } \\
\cline { 2 - 3 } & Sem adição de óleo de soja & Com adição de óleo de soja \\
& $46,5: 53,5$ & $52,7: 47,3$ \\
\hline PB (\%) & 16,6 & 17,2 \\
FDN (\%) & 34,6 & 34,0 \\
FDA (\%) & 21,7 & 21,3 \\
EE (\%) & 2,8 & 6,1 \\
\hline
\end{tabular}

$\mathrm{PB}=$ proteína bruta; $\mathrm{FDN}=$ fibra detergente neutro; $\mathrm{FDA}=$ fibra detergente ácido; $\mathrm{EE}=$ extrato etéreo.

As vacas foram mantidas em cada dieta durante 22 dias e as coletas realizadas no $19^{\circ}$ dia de tratamento, após completa adaptação à dieta fornecida. Foram coletados $1000 \mathrm{ml}$ de líquido ruminal de cada vaca, filtrados em quatro camadas de gaze e transportados em garrafas térmicas pré-aquecidas $\left(39^{\circ} \mathrm{C}\right)$ sob anaerobiose para o laboratório. O líquido foi centrifugado a $500 \mathrm{x} \mathrm{g}$ por 15 minutos e o sobrenadante foi centrifugado a $10.000 \times$ g por 10 minutos, para obtenção do sedimento celular (bactérias do rúmen), sendo, então, suspenso em metade do volume inicial com meio artificial e usado para incubação com diferentes concentrações de lasalocida e monensina.

$\mathrm{O}$ meio artificial utilizado com $292 \mathrm{mg}$ de $\mathrm{K}_{2} \mathrm{HPO}_{4} \cdot 3 \mathrm{H}_{2} \mathrm{O}, 240 \mathrm{mg}$ de $\mathrm{KH}_{2} \mathrm{PO}_{4}, 480 \mathrm{mg}$ de $\left(\mathrm{NH}_{4}\right)_{2} \mathrm{SO}_{4}, 480 \mathrm{mg}$ de $\mathrm{NaCl}, 100 \mathrm{mg} \mathrm{MgSO}_{4}$. $7 \mathrm{H}_{2} \mathrm{O}$, 64mg de $\mathrm{CaCl}_{2}$. $2 \mathrm{H}_{2} \mathrm{O}, 4000 \mathrm{mg}$ de $\mathrm{Na}_{2} \mathrm{CO}_{3}$ e $600 \mathrm{mg}$ de cisteína (Lana e Russell, 1996), foi autoclavado por 15 minutos.

Adicionaram-se $1,4 \mathrm{ml}$ do meio em tubos de ensaio (10ml de volume), para o teste de resistência bacteriana à perda de potássio, acrescentado-se $0,1 \mathrm{ml}$ de solução de etanol (99\%) com níveis crescentes de lasalocida e monensina - $0 ; 0,16 ; 0,31 ; 1,25$ e $5 \mu \mathrm{M}$ como concentração final -, seguindo-se vedação com tampa de borracha e incubação de 10 minutos a $39^{\circ} \mathrm{C}$ em anaerobiose. Foi coletado $1 \mathrm{ml}$ de amostra em tubos de $1,5 \mathrm{ml}$ e centrifugada a $10.000 \times \mathrm{g}$ por cinco minutos, por meio de uma camada de 0,3ml de óleo (mistura 75:25 de óleos $^{12}$ ). De acordo com Lana e Russell (1996), os tubos foram congelados a $-20^{\circ} \mathrm{C}$ e os sedimentos celulares removidos pelo corte de sua parte inferior, sendo as células digeridas em ácido nítrico a $3 \mathrm{~N}\left(\mathrm{HNO}_{3}\right)$ em mesmo volume

'Óleo de silicone DC 556 - Dow Corning Co. - Midland, EUA.

${ }^{2}$ Óleo aditivo - Bardhal - Seattle, EUA. final do meio. $\mathrm{O}$ resíduo não digerido foi removido por centrifugação 10.000 x g por cinco minutos e o potássio foi determinado em espectrofotômetro de chama. A perda de potássio intracelular foi estimada em relação às amostras incubadas sem ionóforo. A perda máxima de potássio $\left(\mathrm{K}_{\max }\right)$ pode ser obtida pela recíproca do inverso do intercepto da ordenada (1/a) e a concentração de monensina necessária para causar a metade da perda máxima $(\mathrm{Kd})$ pela divisão da inclinação da reta pelo intercepto da ordenada (b/a).

O experimento foi realizado em quadrado latino balanceado com quatro períodos de 22 dias e duas repetições nas análises de laboratório. Fezse análise de regressão da recíproca da perda de potássio intracelular em função da recíproca da concentração de monensina para se determinarem a perda máxima de potássio $\left(\mathrm{K}_{\max }\right)$ e a concentração de monensina necessária para causar a metade da perda máxima de potássio $\left(\mathrm{K}_{\mathrm{d}}\right)$, segundo Lana e Russell (1996). Utilizou-se o procedimento ANOVA do pacote estatístico SAS (User's..., 1999) que incluía os efeitos principais e a interação. A comparação de médias foi feita pelo teste Tukey $(\mathrm{P}<0,05)$.

No segundo estudo, duas vacas mestiças (Holandês x Zebu) lactantes, fistuladas no rúmen e estabuladas, foram utilizadas apenas como doadoras de líquido para medir a produção total de gases in vitro (Theodorou et al.,1994).Os animais recebiam a mesma dieta, numa relação concentrado: volumoso de 45:55, com 16\% de proteína bruta, $34 \%$ de fibra detergente neutro, $21 \%$ de fibra detergente ácido e 2,8\% de extrato etéreo. Os animais foram alimentados duas vezes ao dia, às 7 e 15h, e a coleta de líquido ruminal foi realizada duas horas após a alimentação da manhã.

Foram coletados três litros de líquido ruminal, um e meio de cada vaca, filtrado em quatro 
camadas de gaze e acondicionado em garrafas térmicas pré-aquecidas $\left(39^{\circ} \mathrm{C}\right)$ sob anaerobiose para serem transportados ao laboratório. $\mathrm{O}$ líquido foi deixado em repouso por 30 minutos e utilizado apenas como inóculo para a prova de produção de gases in vitro com amostras das dietas 1 e 3 do primeiro estudo. As amostras das dietas foram secas em estufa de ventilação forçada a $55-60^{\circ} \mathrm{C}$ por $72 \mathrm{~h}$ e moídas a $1 \mathrm{~mm}$ para posterior incubação.

Utilizou-se o meio artificial tamponante de McDougal (1949) adaptado por Silva e Queiroz (2002), com 9,8g de $\mathrm{NaHCO}_{3}, 0,57 \mathrm{~g}$ de $\mathrm{KCl}$, $0,47 \mathrm{~g}$ de $\mathrm{NaCl}, 0,05 \mathrm{~g}$ de $\mathrm{CaCl}_{2} \cdot 2 \mathrm{H}_{2} \mathrm{O}, 7 \mathrm{~g}$ de $\mathrm{NaHPO}_{4} \cdot 7 \mathrm{H}_{2} \mathrm{O}$ e $0,12 \mathrm{~g}$ de $\mathrm{MgSO}_{4} .7 \mathrm{H}_{2} \mathrm{O}$, e pH corrigido para 6,8 com $\mathrm{CO}_{2}$.

Aproximadamente $100 \mathrm{mg}$ de cada ração foram colocadas em frasco de vidro $(50 \mathrm{ml})$, em duplicata, adicionados de 7,8ml de tampão McDougal, 0,2ml de antibiótico (monensina ou lasalocida a $5 \mu \mathrm{M}$ de concentração final em solução de álcool etílico $99 \%$ ou própolis a $4 \mathrm{mg} / \mathrm{ml}$ de álcool etílico 99\%) ou, álcool etílico puro $(99 \%)$ para as amostras-controle e $2 \mathrm{ml}$ de inoculo sob saturação de $\mathrm{CO}_{2}$, para promover anaerobiose nos frascos. Os frascos foram vedados com tampas de borracha e lacrados com capas de alumínio e mantidos em sala climatizada a $39^{\circ} \mathrm{C}$ sobre mesa de agitação orbital automática a 44rpm durante 144 horas (Theodorou et al., 1994).

As leituras da pressão e do volume dos gases foram realizadas por meio de voltímetro, nos tempos de 1, 2, 3, 4, 5, 6, 9, 12, 18, 24, 30, 36, $48,60,72,84,96,120$ horas após o início da incubação. No momento inicial da incubação, todos os frascos foram padronizados para a pressão atmosférica mediante punção com agulha. A conversão dos valores observados por intermédio do voltímetro (mvolt), em volume de gases $(\mathrm{ml})$, foi realizada considerando-se que 1 mvolt corresponde a $8,68 \mathrm{ml}$ de gases (Pell e Schofield, 1993).

Os valores do volume acumulado de gases foram submetidos à análise de variância e a comparação de médias foi feita pelo teste Tukey $(\mathrm{P}<0,05)$, por meio do programa SAS (User's..., 1999). O delineamento experimental utilizado foi o inteiramente ao acaso em esquema fatorial
$2 \times 4 \times 2$, duas dietas - controle e dieta básica $+4 \%$ de óleo de soja - e quatro tratamentos - controle, monensina, lasalocida e própolis -, e duas repetições - 2 tubos.

\section{RESULTADOS E DISCUSSÃO}

Nas bactérias provenientes do líquido ruminal das vacas alimentadas com diferentes dietas, com ou sem monensina e/ou óleo de soja, incubadas em meio artificial a $39^{\circ} \mathrm{C}$ por 10 minutos, mostrou-se perda de potássio dependente da concentração de monensina ou lasalocida (Fig. $1)$.

Embora a técnica tenha apresentado alto coeficiente de variação das características analisadas, a população de bactérias obtida do líquido do rúmen das vacas alimentadas com a dieta $4\left(\mathrm{~K}_{\max }=19,9 \%\right)$ foi mais resistente à lasalocida in vitro que a população de bactérias obtida das vacas submetidas à dieta $1\left(\mathrm{~K}_{\max }=\right.$ $30,1 \%)$. O mesmo ocorreu com os animais da dieta 2 , em que a menor perda de potássio $\left(\mathrm{K}_{\max }\right)$ foi $6,5 \%$ e a maior $29,5 \%$ (Tab. 2). Isso confirma que há maior resistência à perda do potássio intracelular pela ação de monensina ou lasalocida in vitro na população de bactérias do rúmen proveniente de animais submetidos às dietas com lipídios e/ou monensina. Estes resultados confirmam os já obtidos por Lana e Russell (1996) e por Leopoldino et al. (2005).

Nas vacas submetidas à dieta 2 , a quantidade de monensina $\left(\mathrm{K}_{\mathrm{d}}=2,3 \mu \mathrm{M}\right)$ in vitro necessária para causar metade da perda máxima de potássio intracelular foi 13 vezes maior $(\mathrm{P}<0,05)$ que a quantidade usada $(0,177 \mu \mathrm{M})$ em vacas submetidas à dieta 1 , porém sem alterar a perda máxima de potássio $\left(\mathrm{K}_{\max }\right)$. Isto significa que a população de bactérias do rúmen tornou-se mais resistente à monensina in vitro, devido ao seu uso na dieta. A quantidade de lasalocida para causar a metade da perda máxima de potássio intracelular não foi diferente entre os tratamentos. Entretanto, pode-se inferir que há necessidade de baixa concentração de lasalocida $(0,218 \mu \mathrm{M})$ para causar a metade da perda máxima em bactérias provenientes de vacas submetidas à dieta 2 , e de alta concentração de monensina (2,3 $\mathrm{MM}$; Tab. 2). 

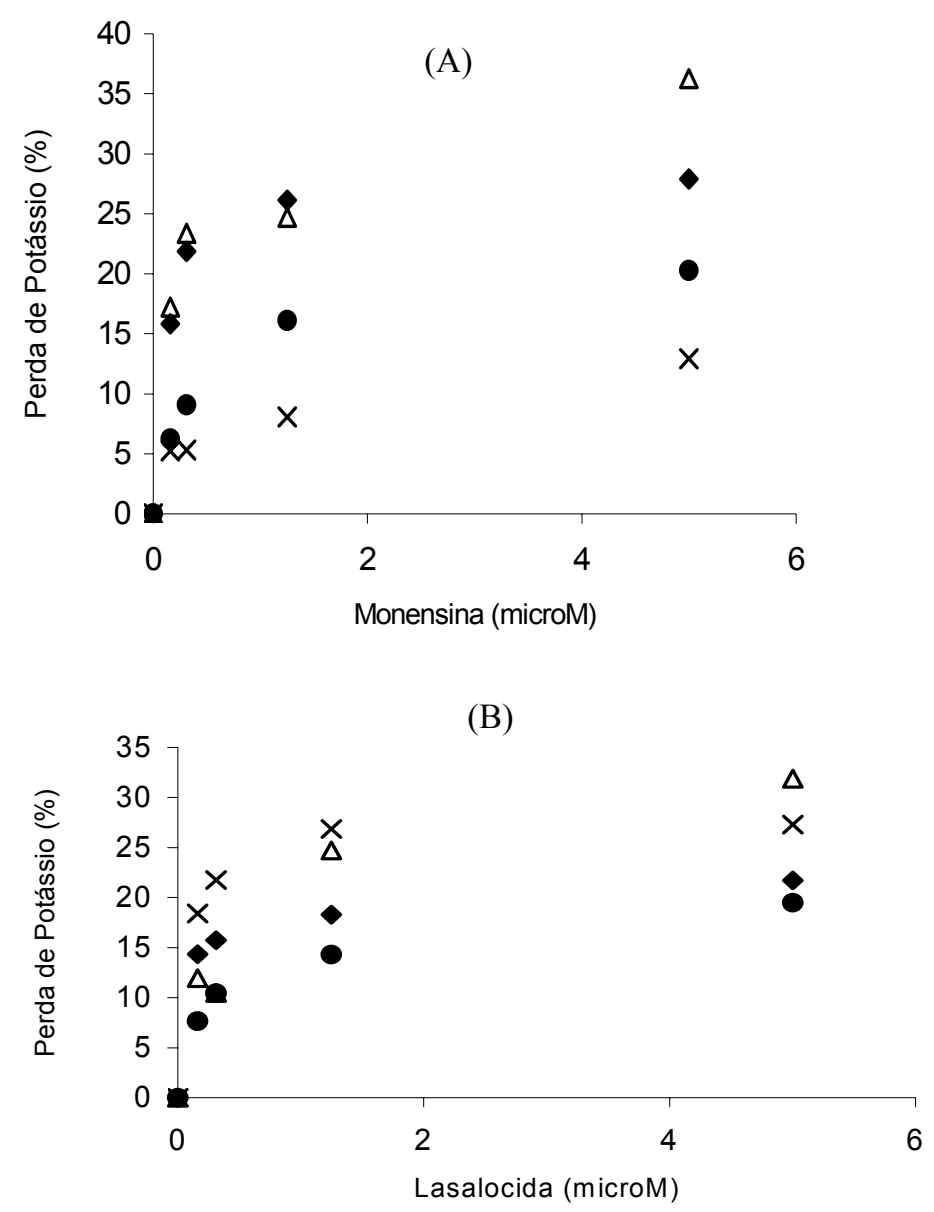

$\Delta$ Controle

Monensina

- Óleo de soja $\quad \times$ Monensina e óleo

Figura 1 - Perda de potássio intracelular de populações de bactérias do rúmen de vacas lactantes submetidas a dietas com ou sem monensina ou óleo de soja, incubadas em meio artificial contendo níveis crescentes de monensina (A) ou lasalocida (B) por 10 minutos a $39^{\circ} \mathrm{C}$. Cada ponto é a média de oito observações.

Tabela 2. Constantes de resistência $\left(\mathrm{K}_{\mathrm{d}}\right.$ e $\left.\mathrm{K}_{\max }\right)$ de populações de bactérias do rúmen de vacas lactantes submetidas a dietas com ou sem monensina ou óleo de soja, incubadas com níveis crescentes de lasalocida ou monensina por 10 minutos a $39^{\circ} \mathrm{C}$

\begin{tabular}{lcccc}
\hline \multirow{2}{*}{ Dietas } & \multicolumn{2}{c}{ Lasalocida } & \multicolumn{2}{c}{ Monensina } \\
\cline { 2 - 5 } & $\mathrm{K}_{\mathrm{d}}(\mu \mathrm{M})^{1}$ & $\mathrm{~K}_{\max }(\%)^{2}$ & $\mathrm{~K}_{\mathrm{d}}(\mu \mathrm{M})^{1}$ & $\mathrm{~K}_{\max }(\%)^{2}$ \\
\hline Dieta 1 & $0,225 \mathrm{a}$ & $30,1 \mathrm{a}$ & $0,177 \mathrm{~b}$ & $29,5 \mathrm{a}$ \\
Dieta 2 & $0,218 \mathrm{a}$ & $19,4 \mathrm{~b}$ & $2,300 \mathrm{a}$ & $28,7 \mathrm{a}$ \\
Dieta 3 & $0,183 \mathrm{a}$ & $25,4 \mathrm{ab}$ & $0,095 \mathrm{~b}$ & $35,6 \mathrm{a}$ \\
Dieta 4 & $0,131 \mathrm{a}$ & $19,9 \mathrm{~b}$ & $0,161 \mathrm{~b}$ & $6,5 \mathrm{~b}$ \\
\hline
\end{tabular}

Médias seguidas de letras distintas na coluna diferem entre si pelo teste Tukey $(\mathrm{P}<0,05)$.

Dieta 1: sem ionóforo e sem óleo de soja;, Dieta 2: 33ppm de monensina, Dieta 3: 4\% de óleo de soja; Dieta 4: $33 \mathrm{ppm}$ de monensina e $4 \%$ de óleo de soja.

${ }^{1}$ Quantidade de ionóforo necessária para causar a metade da perda máxima de potássio das bactérias ruminais após 10 minutos de incubação.

${ }^{2}$ Perda máxima de potássio das bactérias ruminais após 10 minutos de incubação. 
A monensina aumentou a resistência das populações de bactérias do rúmen e não houve resistência cruzada entre os dois ionóforos testados in vitro, ou seja, bactérias de vacas submetidas a dietas com monensina são ainda sensíveis à lasalocida. Isso pode ser atribuído a diferenças no modo de ação (metal/próton antiporte), pois a lasalocida se liga a íons metálicos e prótons, com alta afinidade por $\mathrm{K}^{+}$, enquanto a monensina tem maior afinidade por $\mathrm{Na}^{+}$(Pressman, 1973; 1976).

Quanto à produção cumulativa de gases in vitro, houve interação entre adição de óleo de soja nas dietas das vacas e antibióticos in vitro $(\mathrm{P}<0,03)$. As amostras tratadas com própolis foram as que produziram menor volume total de gases $(12,9 \mathrm{ml} / 100 \mathrm{~g}$ de $\mathrm{MS})$, tanto nas dietas sem óleo de soja quanto nas com óleo de soja, seguidas pela produção de gases das amostras com monensina e lasalocida (Tab. 3).

A própolis foi eficiente em inibir a produção de gases in vitro pela população de bactérias do rúmen, como mostram resultados de produção total de gases para dietas (volumoso + concentrado) incubadas com monensina ou própolis (Stradiotti et al., 2002). De acordo com Schofield et al. (1994), a redução no volume final de gases é provavelmente devido à conservação de carbono no meio. Essa conservação no rúmen decorre da concentração molar de propionato (três carbonos) no rúmen, em detrimento da redução da concentração de acetato (dois carbonos).

Tabela 3. Médias de volume acumulado de gases (ml/100mg de MS) das dietas-controle, com lasalocida, monensina ou própolis, incubadas a $39^{\circ} \mathrm{C}$ durante 120 horas

\begin{tabular}{lll} 
Tratamento & Dieta 1 & Dieta 3 \\
\hline Controle & $22,0 \mathrm{Aa}$ & $19,9 \mathrm{Ba}$ \\
Lasalocida $(5 \mu \mathrm{M})$, & $16,4 \mathrm{Ab}$ & $15,9 \mathrm{Bb}$ \\
Monensina $(5 \mu \mathrm{M})$ & $14,6 \mathrm{Ac}$ & $14,4 \mathrm{Ac}$ \\
Própolis $(40,02 \mathrm{mg} / \mathrm{ml})$. & $12,9 \mathrm{Ad}$ & $12,9 \mathrm{Ac}$ \\
\hline
\end{tabular}

Dieta 1: sem ionóforo e sem óleo de soja; Dieta 3: com 4\% de óleo de soja.

Médias seguidas de letras distintas, maiúsculas na linha e minúsculas na coluna, diferem entre si pelo teste Tukey $(\mathrm{P}<0,05)$.

As amostras incubadas com própolis reduziram em $41,4 \% \quad(9,1 \mathrm{ml} / 100 \mathrm{mg}$ de $\mathrm{MS})$ e $35,2 \%$ $(7 \mathrm{ml} / 100 \mathrm{mg}$ de $\mathrm{MS})$ a produção de gases para as dietas sem e com óleo de soja, respectivamente. Isso resulta em menor eliminação de metano e conseqüentemente, em conservação de carbono no meio com redução na perda de energia. Ao considerar que do total de gases produzidos 53\% são metano (Ezequiel e Gastaldi, 2002), tem-se que a própolis é responsável por diminuir de 18,6 a $21,9 \%(3,7$ a $4,8 \mathrm{ml} / 100 \mathrm{mg}$ de $\mathrm{MS})$ o metano que seria eliminado para o meio. Em experimento in vitro, Czerkawisk e Brekckeringe (1973) verificaram redução de 20 a $30 \%$ da produção de metano com propilenoglicol. Se cada $1 \mathrm{ml}$ de metano corresponder a 8,25 calorias, há uma economia de até $39,6 \mathrm{cal} / \mathrm{mg}$ de MS devido à utilização da própolis na incubação.

Quando se comparam os tratamentos com antibiótico e as dietas com e sem óleo, observase que houve diferença nos tratamentos sem antibiótico e lasalocida, ou seja, houve efeito do óleo de soja na redução de volume de gases nos tratamentos controle - dieta $1(22,0$ vs $19,9 \mathrm{ml} / 100 \mathrm{mg}$ de MS) e lasalocida (16,4 vs $15,9 \mathrm{ml} / 100 \mathrm{mg}$ de $\mathrm{MS}$ ). O óleo de soja foi responsável por reduzir a produção de gases em $9,54 \%(2,1 \mathrm{ml} / 100 \mathrm{mg}$ de $\mathrm{MS})$, o que equivale a menos $5 \%$ de metano, o que resultou em economia de energia.

\section{CONCLUSÕES}

As populações de bactérias do rúmen de animais submetidos a dietas que contenham lipídios ou monensina são mais resistentes à perda do potássio intracelular pela ação da lasalocida. Deve-se ter atenção ao fornecer o ionóforo na dieta de animais que já tenham recebido lipídios ou ionóforos na dieta. A quantidade de monensina é maior do que a de lasalocida para causar metade da perda máxima de potássio na população de bactérias do rúmen de vacas submetidas à alimentação com monensina, e indica que bactérias de animais que recebem monensina são ainda sensíveis à lasalocida. Os antibióticos foram efetivos em reduzir o volume 
de gases, com maior ação da própolis. A própolis leva a redução de metano, o que resulta em maior diminuição da perda de energia para o meio.

\section{REFERÊNCIAS BIBLIOGRÁFICAS}

BATEMAN, H.G.; JENKINS, T.C. Influence of soybean oil in high fiber diets fed to non lactating cows on ruminal unsaturated fatty acids and nutrient digestibility. J. Dairy Sci., v.81, p.2451-2458, 1998.

CHYNOWETH, D.P. Environmental impact of biomethanogenesis. Environ. Monit. Asses., v.42, p.3-18, 1996.

CHOW, J.M.; RUSSELL, J.B. Effect of ionophores and $\mathrm{pH}$ on growth of Streptococcus bovis in batch and continuous culture. Appl. Environ. Microbiol., v.56, p.1588-1593, 1990.

CHOW, J.M.; VAN KESSEL, J.A.S.; RUSSELL, J.B. Binding of radiolabeled monensin and lasalocid to ruminal microorganisms and feed. J. Anim. Sci., v.72, p.1630-1635, 1994.

CZERKAWISK, J.W.; BREKCKERINDGE, G. Dissimulation of 1,2-propanediol by rumen microorganisms. Br. J. Nutr., v.29, p.317-330, 1973.

EZEQUIEL, J.M.B.; GASTALDI, K.A. Proporções de metano, gás carbônico e oxigênio no rúmen de bovinos alimentados com dietas com diferentes relações volumoso:concentrado e fenos de duas qualidades nutricionais. In: REUNIÃO ANUAL DA SOCIEDADE BRASILEIRA DE ZOOTECNIA, 39., 2002, Recife. Anais ... Recife: SBZ, 2002. (CD ROM).

HENDERSON, C. The effects of fatty acids on pure cultures of rumen bacteria. J. Agric. Sci.,v.81, p.107-112, 1973.

JENKINS, T.C. Symposium: Advances in ruminant lipid metabolism - Lipid metabolism in the rumen. J. Dairy Sci., v.76, p.3851-3863, 1993.

LANA, R.P.; RUSSELL, J.B. Use of potassium depletion to assess adaptation of ruminal bacteria to ionophores. Appl. Environ. Microbiol., v.62, p.4499-4503, 1996.

LEOPOLDINO, W.M.; LANA, R.P.; BORGES, A.C. et al. Efeito do $\mathrm{pH}$ in vitro sobre a resistência de bactérias do rúmen à perda de potássio intracelular e efeito do $\mathrm{pH}$ e de ionóforos sobre a produção de amônia e proteína microbiana. Arq. Bras. Med. Vet. Zootec., v.57, p.777-783, 2005.

McDOUGAL, E.I. Studies on ruminal saliva. 1. The composition and output of sheeps saliva. Biochem. J., v.43, p.99-109, 1949.

NAGARAJA, T.G.; NEWBOLD, C.J.; VAN NEVEL, C.J. et al. In: HOBSON, P.N., STEWART, C.S. (Eds). Manipulation of ruminal fermentation. The rumen microbial ecosystem. 2.ed. Great Britain: Blackie Academic e Professional, 1997. p.524-632.

PELL, A.N.; SCHOFIELD, P. Computerized monitoring of gas production to measure forage digestion in vitro. J. Dairy Sci., v.76, p.10631073, 1993.

PRESSMAN, B.C. Properties of ionophores with broad range cation selectivity. Feed. Proc., v.32, p.1698-1703, 1973 .

PRESSMAN, B.C. Biological applications of ionophores. Annu. Rev. Biochem., v.45, p.501$530,1976$.

RUSSELL, J.B.; STROBEL, H.J. Effects of additives on in vitro ruminal fermentation: a comparison of monensin and bacitracin, another Gram-positive antibiotic. J. Anim. Sci., v.66, p.552-558, 1988.

SCHOFIELD, P.; PITT, R.E.; PELL, A.N. Kinetics of fiber digestion from in vitro gas production. J. Anim. Sci., v.72, p.2980-2991, 1994.

SILVA, D.J.; QUEIROZ, A.C. Análise de alimentos: métodos químicos e biológicos. 3.ed. Viçosa: UFV, 2002. 235p

USER'S guide. Release 6.13. Cary, NC: SAS Institute, 1999.

STRADIOTTI, D.; QUEIROZ, A.C.; LANA, R.P. et al. Ação de extrato de própolis sobre a fermentação in vitro de diferentes alimentos. In: REUNIÃO ANUAL DA SOCIEDADE BRASILEIRA DE ZOOTECNIA, 39, 2002, Recife. Anais ... Recife: SBZ, 2002. (CD ROM).

THEODOROU, M.K.; WILLIAMS, B.A.; DHANOA, M.S. et al. A simple gas production method using a pressure transducer to determine the fermentation kinetics of ruminant feeds. Anim. Feed Sci. Technol., v.48, p.185-197,1994. 